\title{
Nickel Oxide Reduction Studied by Environmental TEM and in situ XRD
}

Q. Jeangros ${ }^{1}$, T.W. Hansen ${ }^{2}$, J.B. Wagner ${ }^{2}$, C.D. Damsgaard ${ }^{2}$, R.E. Dunin-Borkowski ${ }^{3}$, C. Hébert ${ }^{1}$, J. Van herle ${ }^{4}$, A. Hessler-Wyser ${ }^{1}$

${ }^{1}$ Interdisciplinary Centre for Electron Microscopy, EPFL, CH-1015 Lausanne

${ }^{2}$ Center for Electron Nanoscopy, Technical University of Denmark, DK-2800 Lyngby

${ }^{3}$ Ernst Ruska-Centre, Jülich Research Centre, D-52425 Jülich

${ }^{4}$ Laboratory for Industrial Energy Systems, EPFL, CH-1015 Lausanne

Nickel oxide reduction and subsequent $\mathrm{Ni}$ behavior under $\mathrm{H}_{2}$ is of practical importance in the field of solid oxide fuel cells (SOFC) as it determines the structure of the electronic conductor on the anode side during operation [1]. Despite extensive coverage in literature [2], some discrepancies remain, notably regarding $\mathrm{NiO}$ reduction kinetics and its structural evolution.

In situ reduction of an industrial $\mathrm{NiO}$ powder from JT Baker ${ }^{\mathrm{TM}}$ is performed under $1.3 \mathrm{mbar}^{\text {of } \mathrm{H}_{2}}$ $\left(2 \mathrm{ml}_{\mathrm{N}} / \mathrm{min}\right)$ in a differentially pumped FEI Titan environmental transmission electron microscope (ETEM) [3]. Images, diffraction patterns and electron energy loss spectra are acquired during different temperature ramps $\left(300\right.$ to $\left.600^{\circ} \mathrm{C}\right)$ to monitor the structural and chemical evolution. Similar experiments are performed in a PANalytical X'Pert PRO X-ray diffractometer equipped with an Anton Paar furnace and a mass spectrometer to complement and extrapolate ETEM data to higher pressure and flow conditions. Peak intensities, crystallite size, $\mathrm{H}_{2}$ and $\mathrm{H}_{2} \mathrm{O}$ signals are monitored.

Reaction kinetics are obtained in the ETEM by electron energy loss spectroscopy using two different techniques based on the change of shape the $\mathrm{Ni} \mathrm{L}_{2,3}$ white lines (either taking the ratio of $\mathrm{Ni}_{3}$ and $\mathrm{L}_{2}$ integrated intensities or using a multiple linear least squares technique $\left.[4,5]\right)$. The results demonstrate that reduction starts below $400^{\circ} \mathrm{C}$ and proceeds quickly until the rate is slowed down at higher temperature and conversion fraction (Fig. 1). Images and diffraction patterns illustrate that $\mathrm{Ni}$ nucleation on $\mathrm{NiO}$ is either epitaxial with a small angle misfit in thin areas (Fig. 2) or randomly oriented in thicker regions. Reduction then proceeds through the growth of Ni nuclei and movement of interfaces, the latter inducing particles shrinkage and intragranular pores creation. Significant densification is observed at temperatures higher than $550^{\circ} \mathrm{C}$ : porosity created at lower temperatures disappears. This reorganization of $\mathrm{Ni}$ is detrimental to the connectivity of the Ni catalyst and to the redox stability of the SOFC.

In situ XRD yields comparable results to ETEM for similar pressure and flow conditions. XRD experiments at different flows and pressures underline the effect of $\mathrm{H}_{2} \mathrm{O}$ removal on the kinetics. $\mathrm{H}_{2} \mathrm{O}$ created upon reaction appears to block $\mathrm{H}_{2}$ access to the reactive sites when the $\mathrm{H}_{2}$ flow is low, an effect observed in both XRD and ETEM experiments.

\section{References:}

[1] Minh, N. Q., Journal of the American Ceramic Society 763 (1993) 563.

[2] Richardson, J. T., R. Scates, et al., Applied Catalysis A: General 2461 (2003) 137.

[3] Hansen, T. W., J. B. Wagner, et al., Materials Science and Technology 2611 (2010) 1338.

[4] Rez, P., E. S. Moore, et al., Microscopy and Microanalysis 14 SUPPL. 2 (2008) 1382.

[5] Van Aken, P. A., B. Liebscher, et al., Physics and Chemistry of Minerals 255 (1998) 323. 


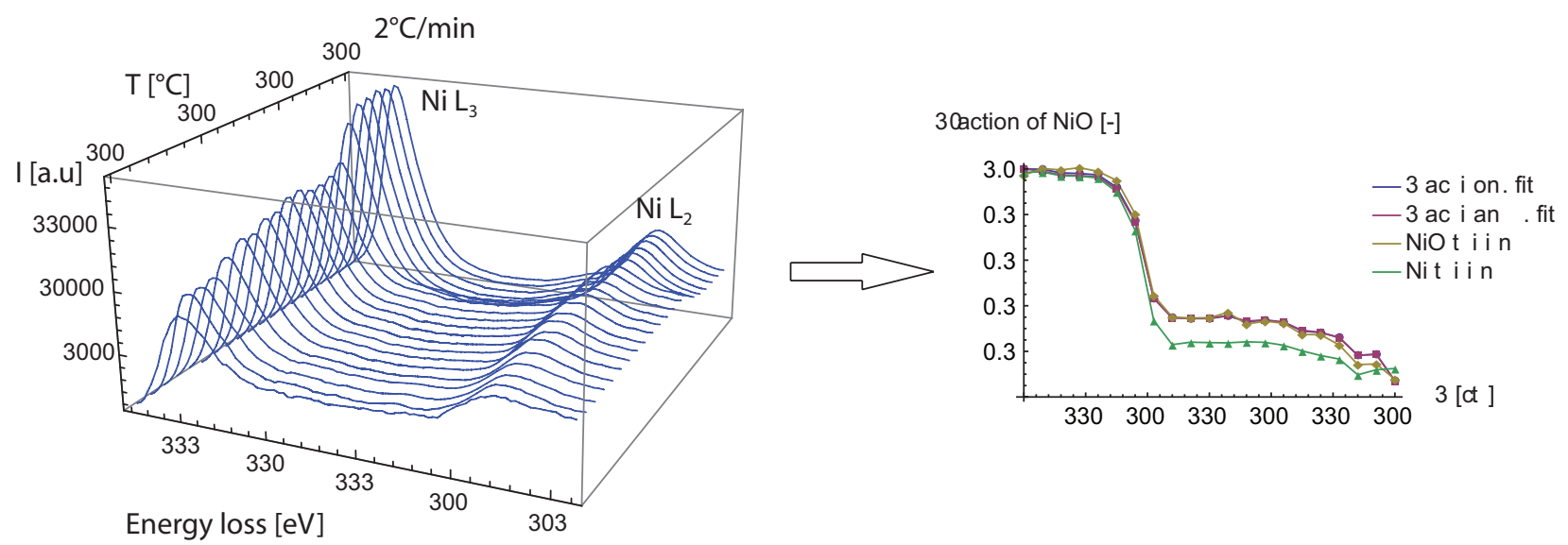

Fig. 1. Electron energy loss spectra evolution as a function of temperature (on the left) are used to extract reduction kinetics (on the right) using the change of shape of the $\mathrm{Ni} \mathrm{L}_{2,3}$ white lines (either using the ratio of the $\mathrm{Ni} \mathrm{L}_{3}$ and $\mathrm{L}_{2}$ intensities integrated with a $2 \mathrm{eV}$ window or using a multiple linear least squares (MLLS) technique, which fits a given spectrum with $\mathrm{NiO}$ and $\mathrm{Ni}$ references).
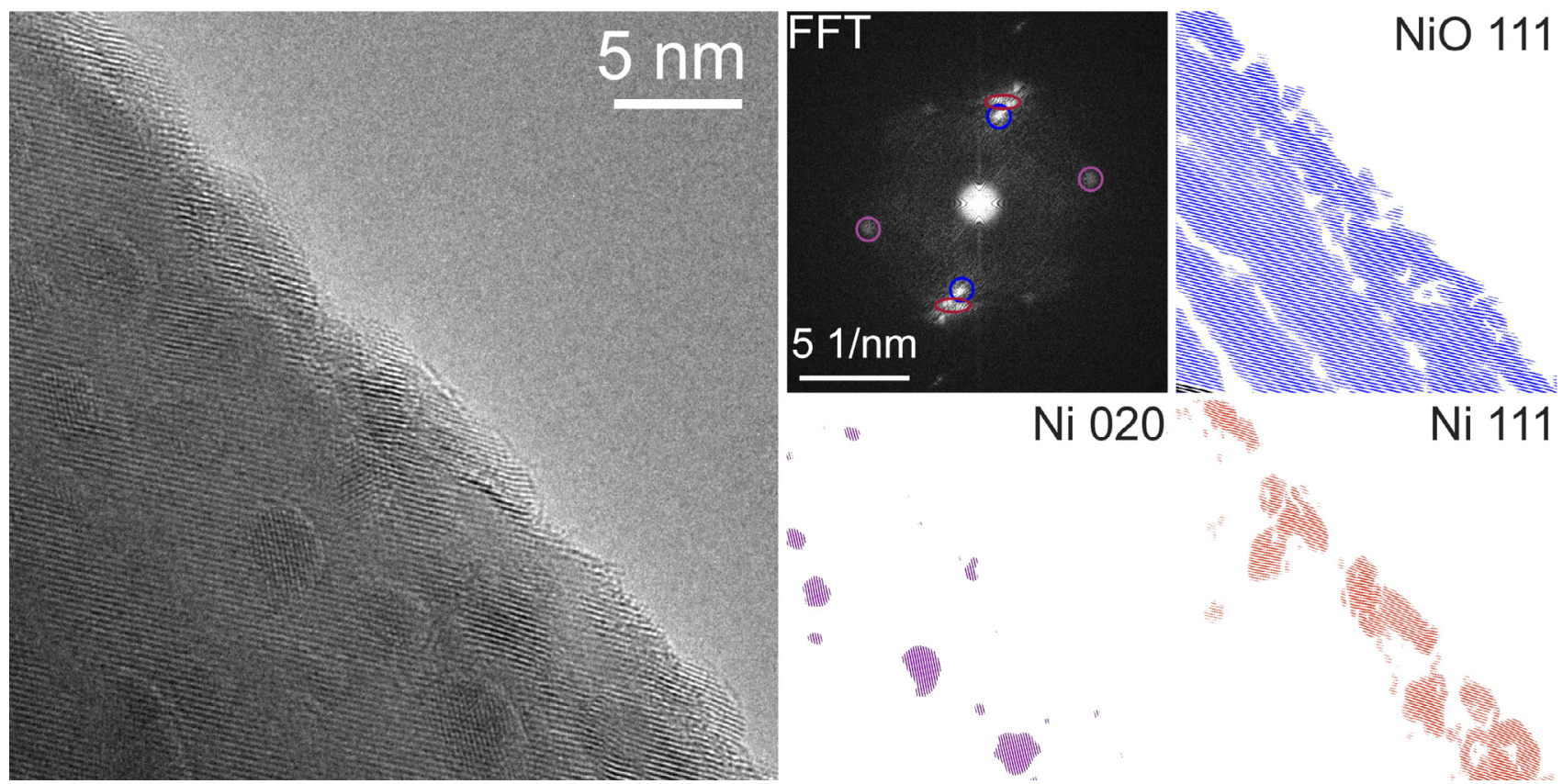

Fig. 2. Ni nucleation on $\mathrm{NiO}$ observed by ETEM at $370^{\circ} \mathrm{C}$. High resolution images, FFT and inverse FFT images illustrate the epitaxial growth of $\mathrm{Ni}$ on $\mathrm{NiO}$ in thin areas (with a small angle misfit resulting in a splitting of the Ni 111 reflections). 